\title{
Bullous disease of the lung and cannabis smoking: insufficient evidence for a causative link
}

\author{
Carol Tan N Hatam Tom Treasure
}

J R Soc Med 2006;99:77-80

Cannabis smoking appears on teaching slides as a cause of bullous lung disease and consequent pneumothorax. This seems to have become received wisdom-'A striking feature of cannabis smoking is that it is associated with bullous lung disease in young people'. ${ }^{1}$ The authors cite a report of four cases. ${ }^{2}$ The suggestion appears, albeit in more muted terms, with the same citation in a UK Parliamentary memorandum on adverse effects of smoking marijuana on lung health. ${ }^{3}$

What is the evidence that cannabis smoking causes bullous lung disease and what is its association, directly or indirectly, with pneumothorax?

The characteristic clinical condition of acute pneumothorax is of a patient who presents with symptoms of rapid onset and is found to have free air in the pleural space. There is a widely accepted taxonomy. ${ }^{4}$ Patients presenting acutely are classified as having spontaneous pneumothorax to distinguish them from those caused by trauma (including iatrogenesis from various interventions with needles in the neck vessels, breast, pleura or lung). Spontaneous pneumothorax is then subdivided dichotomously into primary and secondary.

Secondary spontaneous pneumothorax includes all of those where the pneumothorax occurs in the presence of any underlying lung disease. It is most frequently seen against a background of the common lung diseases that cause enlargement and weakening of the air spaces such as emphysema and chronic obstructive pulmonary disease. Occasional patients have one or more very large bullae. They are usually distinguished from the patient group with chronic obstructive pulmonary disease and emphysema on the basis of younger age and characteristic radiological findings. Is cannabis a cause of these large bullae?

Secondary pneumothorax also occurs in other common diseases such as lung cancer, tuberculosis and lung abscess which may necrose, cavitate and breach the pleura and occasionally present with pneumothorax. There are many much less common diseases such as lymphangioleiomyomatosis, Wegner's granulomatosis, pneumocystis and Langerhans' cell histiocytosis that may present for the first time with pneumothorax. This long and effectively endless

Guy's Hospital, London SE1 9RT, UK.

Correspondence to: Professor Tom Treasure

E-mail: Tom.Treasure@ukgateway.net list of possible causes is not surprising when one notes that the visceral pleura is thin and vulnerable and arguably any lung disease can result in pneumothorax occasionally. ${ }^{4}$

Primary spontaneous pneumothorax is the characteristic condition of young people, predominately males (3:1) in their teens to mid thirties (Figure 1). They tend to be tall and lean; a family history is not infrequent. They fall into a well characterized diagnostic frame..$^{5}$ The words 'primary' and 'spontaneous' have a tendency to be conflated with idiopathic or of unknown aetiology but there is a very definite pathological lesion. In most cases there are small bullae apparent at the apex of the lung. Now that surgeons can obtain excellent magnified views at video assisted thoracic surgery computerized tomography 6,7 and radiologists inspect them with high resolution CT there is no mystery about it. Might cannabis smoking contribute to this group? After all bullae must start small and progress over time to become larger.

There is a quite separate way in which cannabis smokers are reported to present with abnormal air in the chest (pneumothorax and/or pneumomediastinum). Instances in case reports are attributed to extreme breath holding, Valsalva, and Müller's manouevres. ${ }^{8-11}$ This is a form of barotrauma which is a well-recognized cause of pneumothorax in intensive care units. If there is a cause-and-effect relationship between cannabis smoking and acute rupture of previously normal lung air spaces due to extreme pressure change, it falls under the diagnostic heading not of spontaneous but of traumatic pneumothorax. The focus in our investigation was on bullous lung disease in cannabis smokers.

\section{METHODS}

- We performed a systematic search of PubMed and Medline seeking evidence for an association between bullous lung disease and cannabis smoking

- We searched for epidemiological data about the prevalence of lung bullae per se

- We searched for clinical series that might provide information about the aetiology of bullous disease

- We searched for pathological evidence concerning the effect of cannabis on the lung

- We looked for information about the rates of cannabis smoking by age and population. 


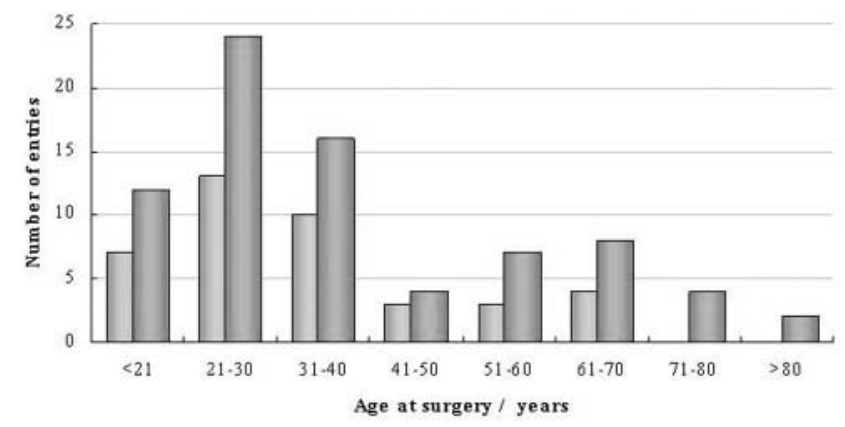

Figure 1 A consecutive series of $\mathbf{1 1 7}$ cases of pneumothorax managed surgically in Guy's Hospital during 2003. It shows the typical bimodal distribution and that males (darker grey bars) outnumber women in both distributions

\section{RESULTS}

\section{Clinical reports of association}

We found 10 cases in four reports ${ }^{2,12-14}$ where the authors have described bullous lung disease in association with cannabis smoking (Table 1). Their ages were 24 to 46, nine were male and all were also tobacco smokers.

\section{Epidemiological evidence about bullous disease prevalence}

The prevalence rate of bullous lung disease in a series of 49902 food handlers undergoing compulsory chest X-ray at the Philadelphia Mass Radiography Unit in 1967 was 1.2 per thousand. ${ }^{15}$ As they relied on $70 \mathrm{~mm}$ images this is likely to be an underestimate. The incidence was higher with increasing age which is what one would expect in any condition which is unremitting and degenerative. In a 5\% sample no bullae were found in non smokers. ${ }^{16}$ In a subsequent publication intriguingly entitled 'Bullous lung disease in short order cooks' they discovered that it was three times higher in those exposed to cooking fumes possibly related to deep frying and working over grills. ${ }^{17}$

\section{Surgical series of bullous disease}

In 1957 the London Chest Hospital ${ }^{18}$ reported 21 operated cases (aged 26 to 65, 18/21 male). The age and sex distribution in this 1950s surgical series and in the $1960 \mathrm{~s}$ epidemiological data are reflected in the ten cases reported in association with cannabis smoking (see Table 1). In 1976 there was a report from Wisconsin of 14 patients operated on between 1955 and 1974 for what they described as giant compressive bullous emphysema or vanishing lung disease $^{19}$; there was a similar series of 14 cases operated on between 1963 and 1969 in Southampton, UK. ${ }^{20}$ The condition was familiar to the authors and the emphasis is on selection of cases for surgical management to relieve breathlessness.

\section{Pathological evidence for damaging effects of cannabis smoking}

We found one large prospective histopathological study in 241 known cannabis smokers ${ }^{21}$ which does not mention

Table 1 Published cases

\begin{tabular}{|c|c|c|c|c|c|c|c|}
\hline Author & $N$ & Age & Sex & $\begin{array}{l}\text { Tobacco smoking } \\
\text { (packs/year) }\end{array}$ & Marijuana smoking & Bulla/empmphysema & Pneumothorax \\
\hline Feldman 1993 (Ref. 12) & 1 & 24 & M & 14 & $\begin{array}{l}\text { Daily }(14-28 \mathrm{~g} / \text { week }) \\
10 \text { years }\end{array}$ & $\begin{array}{l}\text { Right apical bulla (2 further } \\
\text { cases, not reported) }\end{array}$ & Recurrent \\
\hline \multirow[t]{4}{*}{ Johnson 2000 (Ref. 2) } & 4 & 27 & M & 15 & Several pipes/week & Bilateral upper lobe bullae & Yes \\
\hline & & 35 & M & $2-5$ cigars/day & 2 joints/week & $\begin{array}{l}\text { Bilateral paraseptal bullous } \\
\text { emphysema }\end{array}$ & No \\
\hline & & 44 & M & 3 & $2-3$ joints/day & $\begin{array}{l}\text { Bilateral apical peripheral } \\
\text { bullous emphysema }\end{array}$ & No \\
\hline & & 46 & M & 7 & $2-3$ joints/day & $\begin{array}{l}\text { Bilateral multiple large } \\
\text { peripheral bullae in upper lobe }\end{array}$ & No \\
\hline \multirow[t]{2}{*}{ Rawlins 2001 (Ref. 13) } & 2 & 26 & M & Yes & Yes & Bilateral giant bullae & \\
\hline & & 32 & M & Yes & Yes & Bilateral giant bullae & \\
\hline \multirow[t]{4}{*}{ Thompson 2002 (Ref. 14) } & 3 & 33 & M & 9 & $\begin{array}{l}2-3 \text { joints/day } \\
\text { 'heavy' } 10 \text { years }\end{array}$ & Large upper lobe bullae & No \\
\hline & & 45 & $\mathrm{~F}$ & 10 & $\begin{array}{l}\text { Weekends/evenings } \\
\text { 'moderate' } 10 \text { years }\end{array}$ & Large upper lobe bullae & No \\
\hline & & 38 & M & 20 & $\begin{array}{l}0.25 \text { oz marijuana/week, } \\
\text { 'heavy' } 24 \text { years }\end{array}$ & Large upper lobe bullae & No \\
\hline & & & & $\begin{array}{l}\text { Median } \\
34\end{array}$ & & & \\
\hline
\end{tabular}


bullae. The $95 \%$ confidence intervals for $0 / 241$ are $0 \%-$ $1.5 \%$ making any substantial causative link unlikely. Thus far, we have been unable to confirm this with the authors, but if they did not discover any cases among the 241 , it would be compatible with the prevalence of about $1 / 1000$ indicated by epidemiological data. ${ }^{15}$ There is a much smaller pathological report from Australia of 'bong lung' in 10 patients who underwent resection of bullous lung disease. ${ }^{22}$ The author states that as he was not blinded to the smoking history of the subjects this can only be an alert. He draws no conclusions about the aetiology of bullous disease.

\section{Cannabis use}

The use of cannabis among the general population of the European Union has increased since 1990, especially among young adults aged between 15-34 years. Lifetime experience of cannabis use is reported as up to $30 \%$ in Denmark and the UK, with USA figures in a similar range.

\section{DISCUSSION}

Bullous disease is neither a rare nor a new disease. ${ }^{15-20,23-25}$ Based on epidemiological data, among 100000 men in the age group of the cases reported, one might find 116 with bullae evident on chest radiography. Cannabis smoking is common, so the two will occur together by coincidence. But the hypothesis that cannabis actually causes bullous lung disease cannot be totally refuted; it is difficult to prove a negative assertion. Tobacco smoke and other inhaled substances damage the airways ${ }^{21,26,27}$ and there is likely to be an additive effect due to cannabis but its specific role in causing lung bullae must be questioned. Association can easily be interpreted as cause and effect particularly by a mind primed by the literature. . $2,13,14$

The surgical management of lung bullae has undergone renewed interest. It falls within the surgical endeavour now referred to as lung volume reduction surgery. ${ }^{28}$ When that concept was reintroduced 10 years ago it was with the intent of relieving thoracic distension to improve respiratory mechanics ${ }^{29}$ in patients with chronic obstructive pulmonary disease. Its role had been better defined in a multicentre randomized trial. ${ }^{30}$ The favourable group are those with heterogeneous upper lobe predominance, the extreme form of which is of course large apical bullae. It appears that the wheel has come full circle. The emphasis in the older reports was entirely on ridding the patient of bullae that were seen to be a waste of space. ${ }^{18-20,24,25}$

The more common condition, primary spontaneous pneumothorax, is a familiar cause of attendance at accident and emergency departments and of medical admissions. Since it is at its maximum in the teens and twenties, there might be a history of cannabis use in at least $10 \%$ and up to
$30 \%$. As many as a third might be coincidental cannabis smokers. Pneumothorax secondary to cannabis could not by definition fall within this diagnostic frame but on the evidence there is no need to reframe the disease. Lung rupture due to barotrauma is a separate matter.

The phrase 'a striking feature' with reference to lung bullae $^{1}$ is a strong assertion to be referenced only to a report of four patients. Co-authors, reviewers and editors generally provide a series of safety nets to protect us from overstatement but perhaps when sex, drugs and rock and roll are involved, titillation clouds reason. Some people who take Viagra (sildenafil) die (indeed all people who take Viagra will eventually die) but it took the medical statistician Stephen Senn to remind readers of the Big Issue that it does not follow that it was the Viagra that killed them. ${ }^{31,32}$ The association of two factors to imply causation remains common in spite of accessible books dealing with the matter. ${ }^{32-34}$ Building a belief based on isolated instances has its pitfalls as illustrated by the story of the Chinese philosopher Han Fei Tzu who died in 233 BC:

'Once there was a boy told by his master to catch a hare. He went out... lo and behold he saw a hare running along at full speed. As he watched in astonishment, the hare ran smack into a tree and knocked itself unconscious. For the rest of his life the boy waited behind the same tree in the hope that more hares would do the same thing.'

We are not the first to question the strength and validity of assertions about cannabis and health. A BMJ editorial ${ }^{1}$ attracted a very large electronic mail bag, it was criticized for flawed arithmetic ${ }^{35}$ and pilloried in a book on logical thinking. ${ }^{36}$ A subsequent editorial substantially has corrected its message ${ }^{37}$ and put things in better perspective; but the statement about bullae remains uncorrected. It is of great concern that this belief about cannabis and lung bullae should have gained such wide acceptance without the production of better evidence. Perhaps myths are more easily made than forgotten.

Acknowledgment The Research Committee of the British Thoracic Society was asked in June 2004 to investigate the supposed association between cannabis smoking and pneumothorax associated with giant lung bullae. We undertook the task. We agreed that there was insufficient evidence to justify setting up any larger study so these findings are as far as we took the question. We were encouraged by the Chair and Committee to publish our conclusions but the views expressed are those of the authors.

\section{REFERENCES}

1 Henry JA, Oldfield WL, Kon OM. Comparing cannabis with tobacco. BMJ 2003;326:942-3

2 Johnson MK, Smith RP, Morrison D, Laszlo G, White RJ. Large lung bullae in marijuana smokers. Thorax 2000;55:340-2 
3 Britton J. Long-Term Adverse Effects Of Smoking Marijuana On Lung Health, Memorandum 59. London: Royal College of Physicians, 2005 [www.publications.parliament.uk/pa/cm200102/cmselect/cmhaff/ $318 / 318 \mathrm{~m} 78 . \mathrm{htm}]$

4 Tan C. The management of (spontaneous) pneumothorax. In: Treasure T, Keogh SB, Hunt I, Pagano D, eds. The Evidence for Cardiothoracic Surgery. London: TFM; 2005:107-18

5 Rosenberg CE, Golden J. Framing Disease: Studies In Cultural History. New Brunswick: Rutgers University Press, 1992

6 Sedrakyan A, Van Der MJ, Lewsey J, Treasure T. Variation in use of video assisted thoracic surgery in the United Kingdom. BMJ 2004; 329:1011-12

7 Sedrakyan A, van der Meulen J, Lewsey J, Treasure T. Video assisted thoracic surgery for treatment of pneumothorax and lung resections: systematic review of randomised clinical trials. BMJ 2004;329:1008

8 Miller WE, Spiekerman RE, Hepper NG. Pneumomediastinum resulting from performing Valsalva maneuvers during marihuana smoking. Chest 1972;62:233-4

9 Hazouard E, Koninck JC, Attucci S, Fauchier-Rolland F, Brunereau L, Diot P. Pneumorachis and pneumomediastinum caused by repeated Müller's maneuvers: complications of marijuana smoking. Ann Emerg Med 2001;38:694-7

10 Goodyear K, Laws D, Turner J. Bilateral spontaneous pneumothorax in a cannabis smoker. J R Soc Med 2004;97:435-6

11 Birrer RB, Calderon J. Pneumothorax, pneumomediastinum, and pneumopericardium following Valsalva's maneuver during marijuana smoking. N Y State J Med 1984;84:619-20

12 Feldman AL, Sullivan JT, Passero MA, Lewis DC. Pneumothorax in polysubstance-abusing marijuana and tobacco smokers: three cases. $J$ Subst Abuse 1993;5:183-6

13 Rawlins R, Carr C, Brown K, Cameron C, Dussek J. Minerva. BMJ 2001;323:1012

14 Thompson CS, White RJ. Lung bullae and marijuana. Thorax 2002; 57:563

15 Stoloff IL. Bullous disease of the lung detected by mass radiography. Arch Environ Health 1968;17:811-13

16 Stoloff IL, Victor SB. Another hazard of smoking: bullous disease of the lung. Arch Environ Health 1972;25:415-19

17 Stoloff IL. Bullous lung disease in short order cooks. J Occup Med 1973; $15: 202-3$

18 Capel LH, Belcher JR. Surgical treatment of large air cysts of the lung. Lancet 1957;272:759-62
19 Ray JF, III, Lawton BR, Smullen WA, Myers WO, Sautter RD. Effective surgical palliation of giant compressive bullous emphysema (vanishing lung syndrome): long-term follow-up. Am Surg 1976; 42:181-5

20 Wesley JR, Macleod WM, Mullard KS. Evaluation and surgery of bullous emphysema. J Thorac Cardiovasc Surg 1972;63:945-55

21 Fligiel SE, Roth MD, Kleerup EC, Barsky SH, Simmons MS, Tashkin DP. Tracheobronchial histopathology in habitual smokers of cocaine, marijuana, and/or tobacco. Chest 1997;112:319-26

22 Gill A. Bong lung: regular smokers of cannabis show relatively distinctive histologic changes that predispose to pneumothorax. Am J Surg Pathol 2005;29:980-2

23 Morgan MD, Denison DM, Strickland B. Value of computed tomography for selecting patients with bullous lung disease for surgery. Thorax 1986;41:855-62

24 Brantigan O, Mueller E. Surgical treatment of pulmonary emphysema. Am Surg 1957;23:789-804

25 Woo-ming L, Capel L, Belcher JR. The results of surgical treatment of large air cysts of the lung. Br J Dis Chest 1963;57:79-85

26 Tashkin DP. Airway effects of marijuana, cocaine, and other inhaled illicit agents. Curr Opin Pulm Med 2001;7:43-61

27 Tashkin DP, Coulson AH, Clark VA, et al. Respiratory symptoms and lung function in habitual heavy smokers of marijuana alone, smokers of marijuana and tobacco, smokers of tobacco alone, and nonsmokers. Am Rev Respir Dis 1987;135:209-16

28 Whitaker D, Cerfolio R. Lung Volume Reduction Surgery. In: Keogh SB, Pagano D, Treasure T, Hunt I, eds. The Evidence for Cardiothoracic Surgery. London: TFM, 2005:141-54

29 Cooper JD, Trulock EP, Triantafillou AN, et al. Bilateral pneumectomy (volume reduction) for chronic obstructive pulmonary disease. J Thorac Cardiovasc Surg 1995;109:106-16

30 Fishman A, Martinez F, Naunheim K, et al. A randomized trial comparing lung-volume-reduction surgery with medical therapy for severe emphysema. N Engl J Med 2003;348:2059-73

31 Senn S. Viagra is a big flop. Big Issue 1999:82

32 Senn S. Dicing with Death. Cambridge: Cambridge University Press, 2003

33 Gigerenzer G. Reckoning with Risk. London: Penguin, 2002

34 Everitt BS. Chance Rules. New York: Copernicus (Springer-Verlag), 1999

35 Iversen L. Comparing cannabis with tobacco: arithmetic does not add up. BMJ 2003;327:165

36 Whyte J. Bad Thoughts: A Guide To Clear Thinking. London: Corvo, 2003

37 Sidney S. Comparing cannabis with tobacco-again. BMJ 2003; 327:635-6 